\title{
Commentary 3: A response to Lowe
}

\author{
Ian Kennedy Centre of Medical Law and Ethics, King's College, London
}

It may help to remind ourselves why I and others would be writing over twenty years ago about turning off respirators. The short answer is that the law needed to take account of, and take a view on, what was becoming a growing practice. The law, of course, is dynamic. It grows and reshapes itself over time. Medical law is particular proof of this. There is little in the old books on criminal law, for example, which will help the intensive care doctor, save at the most general conceptual level.

So, the law had to take a view. This largely consisted of working from first principles, against a background of certain ethical assumptions and the realities of medical care. Turning off respirators needed to be accommodated within the legal scheme of things, in those circumstances where it was deemed proper to turn them off. By the same token, the limits of the permissible had to be mapped out.

This was not a process that could be conducted in a vacuum. The law had to be applied to new circumstances and, if necessary, developed. But, it could only be developed according to the rules of its own internal structure. What this means is quite complicated. Those like me who were commenting on the law were seeking to state what the law was. Some would describe this as "finding" the law. More honestly, it is a matter of creating it. But, this process of creation or development is always made against the background that the issue at hand could go before a court for decision. Thus, the single most important determinant in developing the law is the sense of what a court would decide. Prediction becomes the key. And, critical to that prediction is the awareness that courts move interstitially. They are reluctant to engage in wideranging reform of the law, regarding that as a matter for parliament. They nudge the law instead, conscious that they have at least three roles in any particular case. They must do justice as between the parties, they must not do violence to the conceptual integrity of the law which they inherit and they must at the same time shape

\section{Key words}

Patients' rights; consent; euthanasia; life-sustaining technology; termination of treatment; acts and omissions. and reshape the law, within its confining borders, to meet new problems. So, this was the background.

Switching off respirators was a challenge because the law of murder had to be negotiated. At first blush, there appears to be an act which the doctor knows will cause death and which, in fact, causes death. These look like the necessary ingredients of the crime of murder. Unless a way of avoiding this view could be identified, doctors would have to be told that they might face prosecution for doing something which they and most others regarded as justified in appropriate circumstances. One proposed way around the problem was to argue that there was no act, but only an omission to act. There are, of course, at least two problems with this argument. First, it is factually implausible. Secondly, it fails to deal with the well-recognised legal objection that, while ordinarily no one is under a duty to help a neighbour, such that omissions to act bring no liability, this is not so when a special relationship exists between the parties, whereby one person has undertaken to help the other. A special relationship brings with it a duty to act, such that an omission to act, if it results in harm, may bring legal liability. The relationship between doctor and patient is just such a special relationship, in which the doctor undertakes to render care and the patient relies on this undertaking.

If the omission fiction is destined to fail, what about relying on the doctrine of causation to avoid the conclusion that we are dealing with murder? On this view, it can be argued that the doctor does not cause the death of the patient by switching off the respirator. The cause is the underlying malady which, in the kind of situation which we are discussing, is fatal in the absence of the respirator. There are admitted difficulties with this approach. The most obvious is that, while it may not be the sole cause, turning the respirator off certainly constitutes a cause. This is particularly so in the hard case which is concentrating our minds here: the patient who is chronically dependent on the respirator but, given support, may live for some period of time. The law does not conventionally insist for causation that the cause be the causa sine qua non. If a cause is a causa causans, this may suffice. Thus, the causation 
argument is difficult and, on its own, may not be entirely convincing.

A further approach, and the one that sparked my article referred to by Lowe, was my suggestion that the law be analysed in terms of the duty owed by the doctor to the patient. This took account of the special relationship recognised by the law and sought to build on it. This is not the place to argue the pros and cons of my article. Readers are referred to it to make up their own minds both as to its plausibility and Lowe's representation of it. Perhaps it may help to say that the article received further thought and elaboration when it appeared in a book of essays, but Lowe was perhaps not referred to this. ${ }^{1}$

\section{Duty to treat}

The argument at its simplest is that a doctor owes a duty to a patient. The competent patient, by giving consent to treatment, seeks the help of the doctor. If the doctor has undertaken to treat, by, for example, accepting the patient as a patient, then the doctor has a duty to treat. If the competent patient refuses consent to treatment or continued treatment, the legal effect is that the doctor is absolved from his or her duty by the patient. Thereafter, the doctor may not impose treatment on the patient. As regards causation, the doctor has caused the termination of treatment, which, once consent was withdrawn, the doctor was obliged in law to do. The subsequent death is caused by the underlying disease which the doctor no longer had authority to treat. The doctor, in short, is not killing the patient but letting him die.

This approach based on duty has not been without its critics. ${ }^{2}$ Bear in mind, however, that it reflected a prediction that a court would not hold a doctor guilty of murder if a respirator were turned off at the patient's request and sought to provide the legal basis for that prediction. The past years have not demonstrated that the prediction was flawed.

But now we come to Lowe's paper. The best place to start may be at the end. A modest proposal is made that will solve all the legal problems. Put respirators on timers. If a patient refuses further treatment, the doctor need not kill (to use Lowe's term) the patient. The respirator is merely not turned on again and the patient dies.

Practical objections to this proposal have no place here. We must leave out of account fears concerning the capacity of the current National Health Service (NHS) to cope with such an idea, backed as it is by the ever-dependable privatised utilities. Instead, we should analyse the proposal to see whether it avoids the problems allegedly associated with turning off the respirator and produces an analytically coherent solution. A key feature of the proposal is that it equates the doctor's response to the patient who refuses further treatment on the respirator to that of the patient refusing dialysis or life-preserving drugs. As regards these latter $\underset{F}{ \pm}$ refusals, the doctor is justified in acceding to them since, apparently, there is no killing involved. Instead, the doctor is simply not continuing treatment in the face of the patient's refusal. This, according to Lowe, would equally apply to not turning the respirator back on.

But, does not parity of reasoning suggest that it applies also when the patient requests that the respirator be turned off? The doctor is absolved from the duty to care, treatment is terminated, death ensues. No, says Lowe. In this case, she says, the doctor would be killing the patient. Well, killing is an awkward word here. If she means that, uniquely in this case, the doctor would be causing the patient's death, this is a hard argument to sustain. She must develop a theory of causation that is both compatible with the general law of causation and also allows her 9 to distinguish the dialysis case from that in which a 0 request is made that the respirator be turned off. If by killing Lowe means that the doctor would be $\bar{\epsilon}$ guilty of murder, then this is obviously question- $\overparen{\Phi}$ begging, since that is the very issue we are trying to $\vec{\oplus}$ sort out. Just asserting it doesn't exactly sort it out. A preliminary conclusion may be, therefore, that Lowe's proposed solution depends for its validity on an analysis which would also, properly applied, appear to justify that which she seeks to exclude from its operation.

If Lowe's solution may be something of a damp squib, we need to ask now why she thought it necessary. The answer in large part was her dissatisfaction with the arguments I and others had previously advanced. She finds them wanting. It may be worthwhile putting one or two of her criticisms under scrutiny. One difficulty raised by the criticisms in her paper is Lowe's use of the word killing. This, as has been noted, is not a technical legal term. It can constitute a factual description of conduct. In such a case it should come with some conceptual overlay concerning causation. Alternatively, it can serve as a surrogate for murder. It is not clear in which sense Ms Lowe uses the word.

\section{Legal culpability}

If it is in the descriptive sense, the relevance of this description of conduct to any discussion of the law must be explained. A soldier may kill an enemy, a surgeon may kill a patient, a host's meal may kill a guest. None of these descriptions say anything about legal culpability. Was the enemy a prisoner of war posing no threat or a sniper about to shoot? Was the patient the recipient of last ditch treatment $\frac{D}{\mathbb{D}}$ which could as well kill or cure or suffering from $\frac{\Omega}{\sigma}$ uncomplicated appendicitis? Did the guest choke on a fish-bone or was the meal poisoned by the host? Thus, for Lowe to say that the patient's request amounts to a request to be killed is not yet to say anything of material consequence for the law. Of $\risingdotseq$ 
course, if it is followed by some analysis demonstrating that this killing is culpable, we will be getting somewhere. Does Lowe do this?

The stark answer must be that she does not. Two of the lines of argument which she advances, however, warrant some attention. The first turns on her understanding of consent in this context. She contrasts turning off the respirator at the patient's request with stabbing him. If, as even I concede, the latter is murder, how can the former, she asks, be made lawful by consent? No patient, nor anyone else, she says, can consent to that which is unlawful. Well, you will notice that the catch is in the last few words. Is turning off the respirator unlawful? Merely asserting that it is will not make it so.

Ms Lowe offers the following by way of justification. She writes that “. . . it is quite indefensible to maintain that one and the same action ... can in one case constitute a morally and legally permissible action while in another it constitutes the crime of murder, depending solely upon whether or not the person whose life is at stake has requested the action. ... The law does not regard the consent of the victim of an act of homicide as in any way disqualifying that act from constituting murder". The words "act of homicide" need some justification. After all, that's what the paper is about. Sadly they receive none, save the bootstrapping reference to killing.

\section{Relevant mental state}

Furthermore, it is elementary that "acts" alone cannot constitute homicide. Regard must also be had to the relevant mental state of the person committing the act. As regards this crucial element, my analysis of the law was and remains as follows. In the case of the doctor who accedes to a patient's request that the respirator be turned off, the question that must be analysed is whether the doctor's intention is culpable. The patient's consent is, of course, relevant to this. While the patient's consent cannot justify that which the law forbids, for example, the direct taking of life, it can justify that which the law allows, for example, the termination of medical treatment. If, therefore, the doctor's intention is to comply with the patient's lawful request, then the conduct is not culpable. Conversely, if the doctor's intention is to do something for or to the patient which the law forbids, then the conduct is culpable. Lowe concedes, in the case of the patient declining dialysis, that it is lawful to terminate treatment when requested to do so. She has to explain, therefore, the theoretical basis for her view that if the means adopted for terminating treatment is turning off the respirator, this is unlawful.

She also has a far greater problem on her hands. She has to explain how it is that, in the case of an incompetent patient, a court can presume to grant an order that a respirator should be turned off. This is no more than the court's refusing consent to further treatment on behalf of the incompetent patient. Lowe's argument, however, would compel her to have to say that the President of the Family Division in the recent case of $\operatorname{Re} R$ (Adult: Medical Treatment $)^{3}$ was authorising the killing of the patient and, therefore, on Lowe's account, was thereby an accessory to murder.

Of course, one of the weaknesses of the analysis which I offered above is that it relies in part on the distinction between conduct which amounts to the direct taking of a patient's life and that which merely involves the termination of treatment. I would be the first to concede that this distinction is one which is hard to sustain on the facts. Indeed, it is undoubtedly unsustainable when pressed. But, it is a distinction which the law currently draws. It allows the law to appear to hold the line against the bogeyman called euthanasia, while permitting doctors to honour a patient's refusal of treatment if this is what the patient wishes. This was what I was saying all those years ago. I also was saying that if this is so for the competent patient who chooses to refuse lifepreserving drugs, it must also be true for the competent patient on a respirator, who otherwise, by virtue of his condition, is trapped and unable to exercise his choice. Respect for this principle cannot depend on whether or not a respirator has a timer. It must, and does, derive from a true understanding of the principles which inform the common law.

Ian Kennedy is Professor of Medical Law and Ethics, School of Law, King's College, London.

\section{References and notes}

1 Kennedy I. Treat me right. Oxford: Oxford University Press, 1991: ch 17.

2 But see Airedale NHS Trust $v$ Bland [1993] 1 All ER 821 and Auckland AHB $v$ Attorney General [1993] NZLR 235.

$3 \operatorname{Re} R$ (Adult: medical treatment) [1996] 2FLR 99. 